\title{
Electron microscopy of biogenic minerals: structure and sizes of uranium dioxide nanoparticles with $\mathrm{Mn}^{2+}$ impurities
}

\author{
E. I. Suvorova \\ A. V. Shubnikov Institute of Crystallography, Federal Scientific Research Centre "Crystallography and Photonics" \\ of Russian Academy of Sciences, Leninsky pr., 59, 19333 Moscow, Russia \\ suvorova@crys.ras.ru
}

PACS 61.46.Df, 68.37.Lp, 87.17.-d

DOI 10.17586/2220-8054-2019-10-2-215-226

\begin{abstract}
Methodological aspects of the extraction of structural and chemical information from transmission electron microscopy (TEM) of uranium dioxide $\left(\mathrm{UO}_{2}\right)$ biogenic nanoparticles are presented. Nanoparticles were formed via the bacterial reduction of water-soluble uranyl acetate with $\mathrm{U}$ (VI) in the presence of $\mathrm{Mn}^{2+}$ ions and cultures Shewanella oneidensis MR-1 in the medium. The particles of $1.2-3.5 \mathrm{~nm}$ in diameter and particle agglomerations were visualized in conventional TEM, high resolution TEM, scanning TEM modes. Their phase and chemical composition were investigated with electron diffraction, X-ray energy dispersive spectrometry and electron energy loss spectroscopy with high spatial resolution. Maintenance of the element balance helped to find the composition of the mixture of $\mathrm{UO}_{2}$ and $\mathrm{Mn}$ acetates. The interpretation of TEM data and modeling allowed to propose the mechanism for the suppression of $\mathrm{UO}_{2}$ particle growth and higher resistance to dissolution of smaller $\mathrm{UO}_{2}$ particles with adsorbed $\mathrm{Mn}$ acetate compared to the larger pure particles.
\end{abstract}

Keywords: uranium dioxide nanoparticles, bacterial reduction, manganese impurity, transmission electron microscopy.

Received: 10 February 2019

Revised: 21 March 2019

\section{Introduction}

One of the primary reasons for investigating the biogenic minerals is to better understand the mechanism of interaction of living organisms and inorganic materials [1]. A direct involving of bacteria in the reduction of metals and metalloids (iron, chromium, uranium, selenium, tellurium and so on) is of considerable interest mainly because of the potential application in the treatment and bioremediation of uranium-contaminated groundwater. The basis of such treatment is the transformation of highly soluble U(VI) salts to sparingly soluble uranium (IV) oxide, uraninite. However, the strategy can be successful if the biogenic uraninite remains immobilized and does not easily oxidize [2]. Therefore, the structure and morphology of biogenic minerals, as well the impurity effect, have been and remain a subject of close attention with a view to addressing problems in fundamental and applied science and in technology.

The presence of different impurities has the potential to complicate the remediation process: change the rates of uranium transformations, influence the size and shapes of precipitated particles, enhance or inhibit dissolution and oxidation of the U(IV) oxide biogenic mineral. Manganese (Mn) is the 10th most abundant element in the Earth's crust and second only to iron as the most common heavy metal and $\mathrm{Mn}$ (II) is readily depleted from igneous and metamorphic rocks by interactions with surface water and groundwater being highly mobile in acidic aqueous systems [3]. Mn (II) presented in groundwater is considered a pollutant mainly because of their organoleptic properties [4]. Therefore, there is a request to develop environmentally friendly ways to remove Mn from water. In this regard, the combination of redox and adsorption processes is very attractive for removing two ions U(VI) and $\mathrm{Mn}(\mathrm{II})$ simultaneously.

Among all the methods available for the study of small particles, analytical transmission electron microscopy (TEM) offers possibilities for visualization in conventional TEM, high resolution TEM (HRTEM), scanning TEM (STEM) modes, investigation of phase (electron diffraction) and element composition (X-ray energy dispersive spectrometry, EDS), determination of chemical and oxidation state (electron energy loss spectroscopy, EELS) of individual particles of a few $\mathrm{nm}$ size, their agglomerations and mixtures of different phases with high spatial resolution. Severe requirements are imposed on thickness of TEM specimens. Clearly interpretable data can be obtained only for thin samples with a thickness of less than $50 \mathrm{~nm}$ and in some cases (for instance, using high-resolution methods) the thickness of the samples should not exceed $10 \mathrm{~nm}$. The electron radiation effect on biogenic minerals can be a big issue. Small particles can change their shape and size, and such changes depend on both the time of irradiation and the intensity of the beam. The electron damage affects the structure and/or the chemistry of specimens when inelastic scattering (heating) breaks the chemical bonds (radiolysis) [5]. 
In this work, the particular interest was in identifying and characterizing the uranium-containing compound produced by metal-reducing bacteria in the presence of $\mathrm{Mn}$ impurities using TEM, electron diffraction, X-ray EDS and EELS. An additional objective is to provide insight methodological aspects, revisiting the TEM data coupling with electron diffraction simulation and structure modeling to propose the mechanism of higher resistance of smaller uraninite particles with adsorbed $\mathrm{Mn}$ acetate compared to the larger pure $\mathrm{UO}_{2}$ particles.

\section{Materials and methods}

\subsection{Cell cultures}

Biogenic samples were prepared under anoxic conditions at École Polytechnique Fédérale de Lausanne (EPFL), Switzerland. All details of preparation of bacterial cultures (Shewanella oneidensis MR-1) for reduction of U(VI) and chemical experiments are given elsewhere [6-9].

\subsection{Reduction of $\mathrm{U}(\mathrm{VI})$ in the presence of $M n$ impurities}

A colony of Shewanella oneidensis MR-1 was grown in LB medium (water, peptide tryptone, yeast extract and $\mathrm{NaCl}$ ). Reduction of $\mathrm{U}(\mathrm{VI})$ from uranyl acetate was carried out at $\mathrm{pH} 6.3$ within $12 \mathrm{~h}$ for most of the conditions. The $\mathrm{MnCl}_{2}$ solution was added to adjust to $0.1,0.25,0.5,1.0,2.5,5.0$ and $8.0 \mathrm{mM}$ concentrations.

The cells and resulting nanoparticles were collected by centrifugation. The resulting pellet was washed with anoxic $\mathrm{H}_{2} \mathrm{O}$. Some part of samples was treated with $1 \mathrm{M} \mathrm{NaOH}$ to remove the biomass and $0.5 \mathrm{M} \mathrm{NaHCO}_{3}$ to remove remaining adsorbed $\mathrm{U}(\mathrm{VI})$ as much as possible. Thus, the two main types of samples were investigated using TEM: samples containing cells and nanoparticles, and samples containing nanoparticles only. $\mathrm{Mn}^{2+}$ adsorbed on the particle surface and weakly bound to it was rinsed off using $25 \mathrm{ml}$ of $20 \mathrm{mM}$ MES (2-(N-morpholino) ethanesulfonic acid) buffer at $\mathrm{pH}$ 5. More details on specimen treatments and chemicals can be found elsewhere [7, $8]$.

\subsection{Transmission electron microscopy}

Samples for TEM study were prepared by drying the colloids of cells with particles on a carbon-coated copper grid (whole mount specimens) or as $50-80 \mathrm{~nm}$ slices of epoxy (Araldite, Epon or DER resin) with embedded cells and particles. In the latter case, bacterial specimens after reduction were fixed in $2.5 \%$ glutaraldehyde and sequentially dehydrated in pure grade ethanol series (from $25 \%$ to $100 \%$ ). The dehydrated cells with nanoparticles were collected by centrifugation and embedded in Araldite resin or Epon resin, then polymerized. The thin slices of polymerized resin were cut with an ultramicrotome using a diamond knife and then placed on copper grids with porous carbon films.

The structure and chemical composition of the particles were studied by conventional TEM, HRTEM, STEM, selected area electron diffraction (SAED), X-ray EDS and EELS in a CM300UT FEG (300 kV field emission gun, $0.65 \mathrm{~nm}$ spherical aberration, and $0.17 \mathrm{~nm}$ resolution at Scherzer defocus) and a Tecnai Osiris (200 kV high brightness XFEG, $0.24 \mathrm{~nm}$ point resolution, a-twin pole piece with Super-X EDX).

The TEM/HRTEM and EEL spectra images were processed with the Gatan Digital Micrograph software. The X-ray EDS microanalysis was performed in STEM mode and quantitative data were derived with the help of INCA (Oxford) and ESPRIT software (Bruker). Quantitative EDS analysis was carried out using the Cliff-Lorimer standard-less method at the nanoscale with thickness correction [5] and in this work were done assuming several possible thickness values from 0 to $60 \mathrm{~nm}$.

The simulation and interpretation of SAED patterns and diffractograms (Fast Fourier transforms) of HRTEM images and structure modeling were performed with the JEMS software package [10] using the known crystal structures and atom positions, electron-optic parameters of the microscopes. The measurement errors in electron diffraction patterns and HRTEM images were about $5 \%$ and $2 \%$, correspondingly.

\section{Results and discussion}

\subsection{Imaging and composition of the biogenic minerals}

The (S)TEM images showed cells coated by nanoparticles and nanoparticle agglomerations in the extracellular space (Figs. 1 and 2). The chemical and phase composition of biogenic minerals were derived from X-rays energy dispersive spectra (Fig. 1(b) and Fig. 2(c,d)) and SAED patterns (Fig. 1(d) and Fig. 2(b)) obtained from nanoparticles. The (S)TEM images in Fig. 1 obtained from the cells embedded in the resin show particles only in the extracellular space and the STEM image in the Fig. 2 taken from the whole mount sample demonstrates completely covered cells by $\mathrm{U}$ oxide particles together with the extracellular agglomerates. 

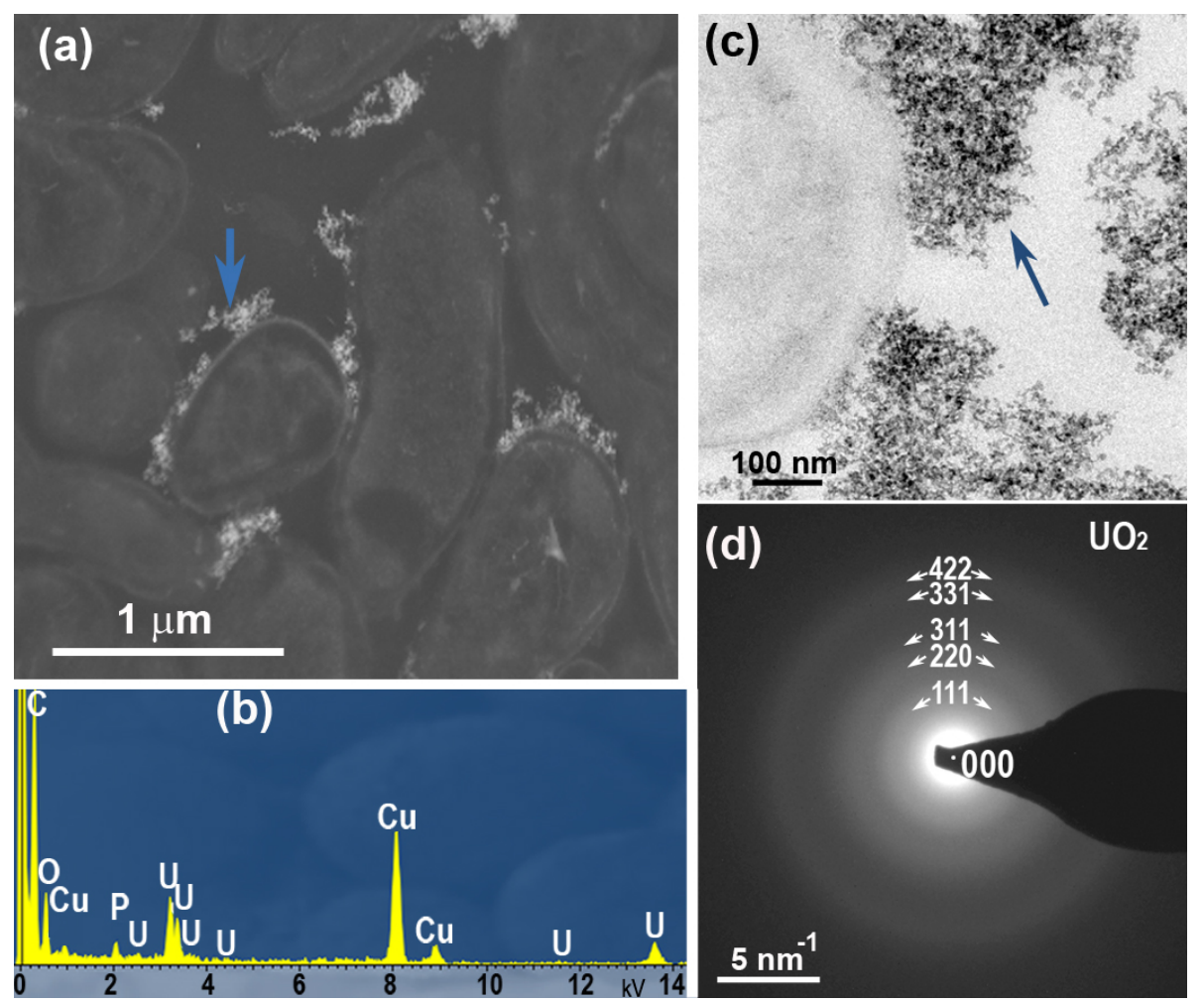

FIG. 1. STEM image of cells and $\mathrm{UO}_{2}$ nanoparticles in an extracellular space embedded in araldite resin (a), X-ray EDS spectrum obtained from the particle agglomeration indicated by arrows (b), TEM image of one of cells and $\mathrm{UO}_{2}$ nanoparticles (c) and the corresponding SAED pattern (d) obtained from the particle agglomeration indicated by an arrow in the TEM image.

The following elements were identified by X-ray EDS: U and $\mathrm{O}$ in the control sample without impurities (Fig. 1(b)), P comes from cells, C comes from cells and from the carbon support, Cu comes from the TEM grid. Chemical analysis of samples in which manganese chloride was added showed that manganese is mainly localized in agglomerates of $\mathrm{UO}_{2}$ (Fig. 2(c, d)), where it is almost 10 times larger than on the surface of bacteria. The presence of chlorine from the $\mathrm{MnCl}_{2}$ precursor was not detected in the dried samples because of complete washing out. Elements $\mathrm{Fe}, \mathrm{Co}, \mathrm{Ni}$ (from the microscope material) and $\mathrm{Cu}$ (from the supporting grid), which were not included in the samples were deconvoluted during quantitative microanalysis.

The phase composition of minerals is derived quite easily from the experimental SAED patterns which were compared with the simulated ones using JEMS for different $\mathrm{U}$ oxides $\left(\mathrm{UO}_{3}, \mathrm{U}_{3} \mathrm{O}_{8}, \mathrm{UO}, \mathrm{UO}_{2}\right.$ and $\left.\mathrm{U}_{4} \mathrm{O}_{9}\right)$. Crystallographic parameters for $U$ oxides are listed in Table 1. Analysis showed that the simulated SAED patterns from the $\mathrm{UO}_{2}$ phase with cubic structure (sp.gr. Fmm, $a=0.544 \mathrm{~nm}$ ) had the best match with the experimental ones despite the broaden rings. The example of such matching is shown in Fig. 2(b). All other oxides (with the exception of UO) should have the reflections closer to the center of the SAED pattern in comparison with the $\mathrm{UO}_{2}$ phase. However, no evidence has been obtained for the presence of reflections from other U oxides.

Quantitative data obtained from X-ray ED spectra showed a significant amount of oxygen which cannot be explained by the presence of $\mathrm{UO}_{2}$ only. Thus, the EDS data led to the assumption that $\mathrm{Mn}$ oxides $\left(\mathrm{MnO}, \mathrm{MnO}_{2}\right.$, $\mathrm{Mn}_{3} \mathrm{O}_{4}$ and $\mathrm{Mn}_{2} \mathrm{O}_{3}$ ) or other compounds containing $\mathrm{Mn}$ and $\mathrm{O}$ are formed. Simulation of ring diffraction patterns from the mixture of $\mathrm{UO}_{2}$ and some $\mathrm{Mn}$ oxides (not presented here) with the crystal parameters listed in Table 1 showed that even for the low content of Mn oxides in mixture of nanoparticles the SAED patterns must contain some reflections closer to the central beam. However the background of experimental SAED pattern corresponded only to the $\mathrm{UO}_{2}$ ring pattern as well $\mathrm{Mn}$ oxide particles were never observed separately from $\mathrm{UO}_{2}$ agglomerates. Precipitates of Mn oxides are characterized by morphology different from that of uranium oxide particles [26,27]. In addition, the concentrations of oxygen extracted from EDS data were high and the balance could not be reached with $\mathrm{U}$ and $\mathrm{Mn}$ oxides. Therefore, it was necessary to find another source of large amounts of oxygen. Among the other compounds, manganese acetates $[28,29]$ could be the potential candidates. 


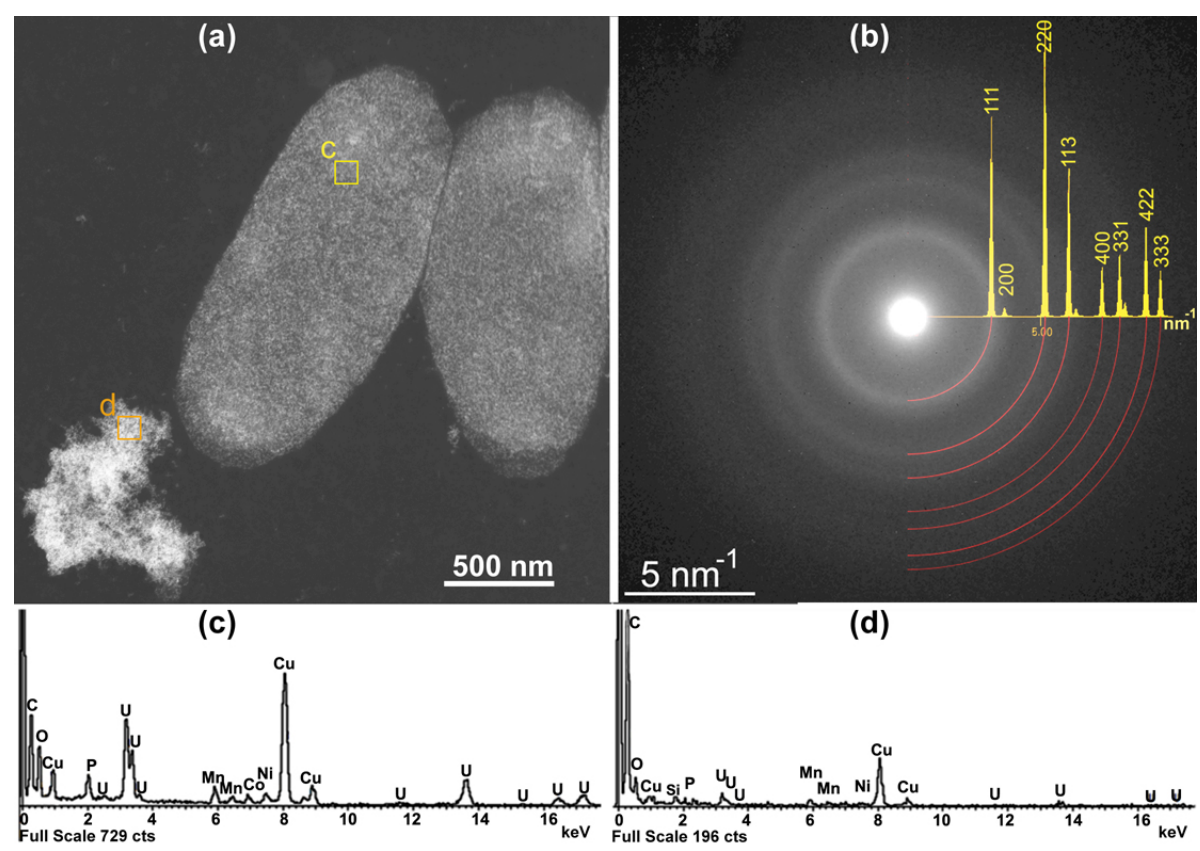

FIG. 2. TEM image of cells covered with $\mathrm{UO}_{2}$ particles and $\mathrm{UO}_{2}$ particles with $\mathrm{Mn}$ impurities in an extracellular space in a whole mount specimen (a), X-ray EDS spectra obtained from the particle agglomeration and the cell ( $b$ and $c)$, SAED pattern obtained from the particle agglomerate $(\mathrm{d}), \mathrm{UO}_{2}$ phase with cubic structure derived using JEMS simulation of the SAED pattern (e)

Acetate ions, being a component of uranyl acetate and one of the major organic acid metabolites [30] after bacterial reduction of $\mathrm{U}$ (VI) can interact with $\mathrm{Mn}^{2+}$ ions and form hydrated manganese (II) acetates and absorbed on the surface of $\mathrm{UO}_{2}$ nanoparticles. It is known that simple mono-carboxylates, such as acetate, are able to generate complex extended structures due to the many accessible carboxylate bridging coordination modes [31]. Thus, the heterogeneous medium with $\mathrm{UO}_{2}$ precipitates facilitates the formation and adsorption of Mn acetates. It also should be noted that in spite that, $\mathrm{Mn}$ acetate is considered as water soluble compound (solubility of tetrahydrate and anhydrous $\mathrm{Mn}$ acetate is $64.5 \mathrm{~g} / 100 \mathrm{ml}$ and $38.1100 \mathrm{ml}$, respectively, at $50{ }^{\circ} \mathrm{C}$ ) the solubility of $\mathrm{MnCl}_{2}$ is much higher $\left(88.5 \mathrm{~g} / 100 \mathrm{ml}\right.$ at $\left.40{ }^{\circ} \mathrm{C}\right)$ [32,33] and therefore Cl-ions are much more easily washed out during rinsing with distilled water.

The formation of manganese acetate dihydrate or/and tetrahydrate corresponds well to elemental concentrations expressed in atomic \% for the samples of assumed realistic thickness ranged from 10 to $60 \mathrm{~nm}$. The plots (Fig. 3) show the actual oxygen concentrations in at.\% depending on thickness for samples containing $\mathrm{UO}_{2}$ particles with $\mathrm{Mn}$ impurities before and after treatment by the $\mathrm{NaOH}$ solution. The curve named "remaining oxygen" shows the remaining oxygen concentration of $\mathrm{O}$ after subtracting oxygen per uranium dioxide, phosphate group and possible silicon oxide. The lines named " $\mathrm{MnAc}_{2}$ tetra", "MnAc $\mathrm{c}_{2}$ dihydr", "MnAc $\mathrm{c}_{2}$ anhydr" and "Mn hydroxide" show the oxygen concentration required to satisfy the corresponding stoichiometric formulas of $\mathrm{Mn}\left(\mathrm{CH}_{3} \mathrm{COO}\right)_{2} \cdot 4 \mathrm{H}_{2} \mathrm{O}$, $\mathrm{Mn}\left(\mathrm{CH}_{3} \mathrm{COO}\right)_{2} \cdot 2 \mathrm{H}_{2} \mathrm{O}, \mathrm{Mn}\left(\mathrm{CH}_{3} \mathrm{COO}\right)_{2}$ and $\mathrm{Mn}(\mathrm{OH})_{2}$. The intersection of these lines with the curve of "remaining oxygen" makes it possible to estimate the thickness of the sample.

Thus, the X-ray EDS data helped to maintain the balance of elements in accordance with the stoichiometric formulas to find the composition of a mixture of phases of $\mathrm{UO}_{2}$ and $\mathrm{Mn}$ acetate tetra- or/and dihydrate within the experimental error.

The $\mathrm{NaOH}$ treatment of samples can lead to transformation of the part of $\mathrm{Mn}$ acetate into Mn hydroxide [34]. However, $\mathrm{Mn}$ acetate stays the main component of the adsorption layer and the $\mathrm{UO}_{2}$ particle shell. This observation is consistent with a well-documented fact of the strong adsorption capacity of $\mathrm{Mn}^{2+}$ salts [35].

Figure 4 shows the structure models of $\mathrm{UO}_{2}$ particles (core) coated by adsorbed manganese acetate tetrahydrate (Fig. 4(a)) on the 2.5-nm carbon film. The profiles of the simulated ring diffraction pattern (Fig. 4(b)) and the simulated ring diffraction patterns (Fig. 4(c)) evidence that the presence of $\mathrm{Mn}$ acetates in the given concentrations did not affect the positions of the peaks in electron diffraction patterns and show the good match with the experimental diffraction patterns. 
TABLE 1. Crystallographic parameters of $U$ and Mn oxides

\begin{tabular}{|c|c|c|c|}
\hline Compound & Space group & Parameters [nm] & References \\
\hline $\mathrm{UO}_{2}$ & Cubic, Fm-3m & $a=0.547$ & {$[11]$} \\
\hline $\mathrm{UO}$ & Cubic, Fm-3m & $a=0.492$ & {$[12]$} \\
\hline $\mathrm{UO}_{3}$ & Tetragonal, I41/am & $\begin{array}{c}a=b=0.6901 \\
c=1.9975\end{array}$ & [13] \\
\hline \multirow[t]{2}{*}{$\mathrm{U}_{3} \mathrm{O}_{8}$} & Hexagonal, P-3 & $\begin{array}{c}a=b=0.6815 \\
c=0.4136\end{array}$ & {$[14]$} \\
\hline & Orthorhombic, C222 & $\begin{array}{c}a=0.6704, b=1.195 \\
c=0.4142\end{array}$ & {$[15]$} \\
\hline $\mathrm{U}_{4} \mathrm{O}_{9}$ & Cubic, I-43d & $a=2.1805$ & {$[16]$} \\
\hline $\mathrm{MnO}$ & $\begin{array}{l}\text { Cubic, Fm-3m } \\
\text { Cubic, Fm-3m }\end{array}$ & $\begin{array}{l}a=0.441 \\
a=0.454\end{array}$ & $\begin{array}{l}{[17]} \\
{[18]}\end{array}$ \\
\hline $\mathrm{MnO}$ & Hexagonal, P63m & $\begin{aligned} a & =0.3372 \\
c & =0.5386\end{aligned}$ & [19] \\
\hline $\mathrm{Mn}_{2} \mathrm{O}_{3}$ & Cub., Ia-3 & $a=0.941$ & {$[20]$} \\
\hline \multirow[t]{2}{*}{$\mathrm{Mn}_{3} \mathrm{O}_{4}$} & Tetragonal, I41/amd & $\begin{array}{c}a=b=0.5757 \\
c=0.9424\end{array}$ & {$[21]$} \\
\hline & Orthorhombic, Pbca & $\begin{array}{c}a=0.9412, b=0.9418 \\
c=0.9423\end{array}$ & {$[22]$} \\
\hline \multirow[t]{3}{*}{$\mathrm{MnO}_{2}$} & Tetr., P 42/mnm & $\begin{array}{c}a=b=0.4398 \\
c=0.2873\end{array}$ & {$[23]$} \\
\hline & Orthorhombic, Fddd & $\begin{array}{c}a=1.2207, b=2.0154 \\
c=0.2725\end{array}$ & {$[24]$} \\
\hline & Orthorhombic, Pnma & $\begin{array}{c}a=0.9273, b=0.2864 \\
c=0.4522\end{array}$ & {$[25]$} \\
\hline
\end{tabular}

The presence of $\mathrm{Mn}$ and high content of oxygen in particle agglomeration and nearly the same U/Mn ratio in $\mathrm{NaOH}$ treated and untreated samples showed that the tendency of $\mathrm{UO}_{2}$ particles to strongly agglomerate was preserved as well the major part of manganese acetate was not dissolved. Therefore, the process of biogenic removal of $\mathrm{U}^{6+}$ from contaminated water can be efficient also for the simultaneous removal of $\mathrm{Mn}^{2+}$ ions.

\subsection{EELS characterization}

Electron energy loss spectroscopy (EELS) was applied to ascertain if mixed chemical states of uranium (for instance, traces of the remaining $\mathrm{U}^{6+}$ ) and manganese can be determined after the bacterial reduction.

A typical EEL spectrum for $\mathrm{UO}_{2}\left(\mathrm{U}^{4+}\right)$ obtained at room temperature with two $\mathrm{U}-\mathrm{M}_{5,4}$ edges $(3552 \mathrm{eV}$ and $3728 \mathrm{eV}$, correspondingly) is present in Fig. 5(a). Applying the comparison of the experimental EEL spectra from the biogenic mineral and synthetic $\mathrm{UO}_{2}$ standard namely M5/M4 white-line ratios [36] led to the conclusion that $\mathrm{U}^{6+}$ changed to $\mathrm{U}^{4+}$ and $\mathrm{UO}_{2}$ particles formed.

However, the efforts to determine the valence state of the impurity $\mathrm{Mn}$ ion in the presence of large quantity of $\mathrm{UO}_{2}$ failed. Fig. 5(b) shows the weak $\mathrm{U}-\mathrm{N}_{7,6}$ edges between 350 and $400 \mathrm{eV}$ and the $\mathrm{O}-\mathrm{K}$ edge corresponding to the $\mathrm{UO}_{2}$ phase while $\mathrm{Mn}-\mathrm{L}_{3,2}$ lines were detected only for the specimens with the highest $\mathrm{MnCl}_{2}$ concentration $(8 \mathrm{mM})$ in the solution. We did not succeed to record clear Mn edges in the specimens with lowest concentration of $\mathrm{Mn}$ ion (when the $\mathrm{UO}_{2}$ particles had the biggest size) [8]. $\mathrm{Mn}-\mathrm{L}_{3,2}$ lines did not appear in the EEL spectrum due two possible reasons: a very low concentration of $\mathrm{Mn}$ ions $\left(0.1 \mathrm{mM}\right.$ in solution) absorbed onto a thick $\mathrm{UO}_{2}$ particle agglomeration. The increase in Mn concentration allowed detection of the $\mathrm{Mn}-\mathrm{L}_{3,2}$ edges. However, EELS 

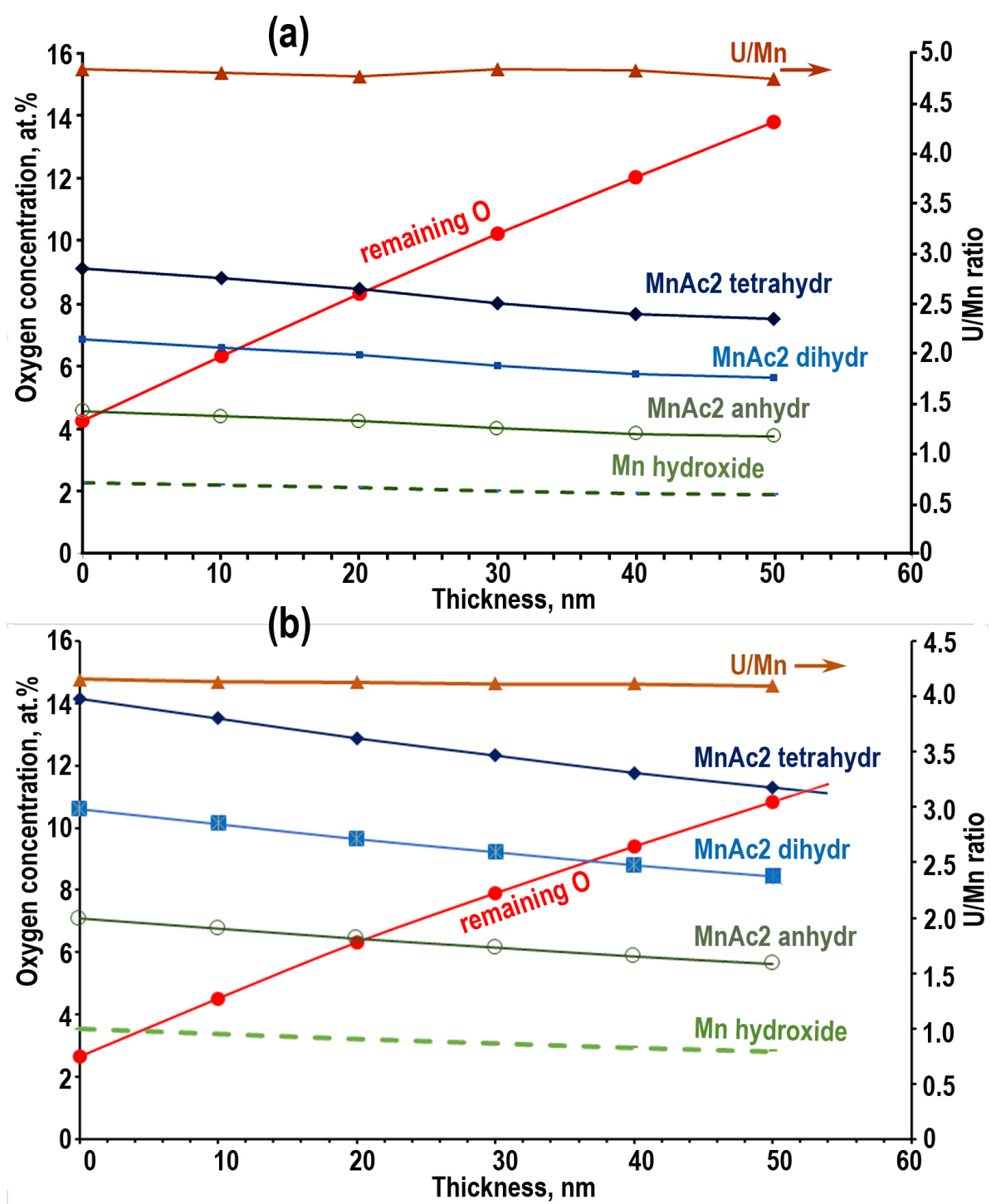

FIG. 3. Oxygen concentration values calculated using absorption correction method in the thickness range from 0 to $60 \mathrm{~nm}$ for untreated samples (a) and for $\mathrm{NaOH}$ treated samples (b). The ratio $\mathrm{U} / \mathrm{Mn}$ is nearly constant and equal $\approx 4.7$ for untreated samples (a) and $\approx 4.2$ for $\mathrm{NaOH}$ treated ones (b)

measurements did not give an unambiguous answer to the question of the valence of $\mathrm{Mn}$ ions, which, again may be due to the insufficient $\mathrm{Mn}$ content and relatively thick $\mathrm{UO}_{2}$ agglomerated specimens.

The significant effect of sample thickness and carbon on the $U$ oxide spectrum in the low-loss region 0 $60 \mathrm{eV}$ [37] is shown in Fig. 5(c, d). Spectrum in Fig. 5(c) was obtained from the thick part of the $\mathrm{UO}_{2}$ particle agglomeration on the carbon support while spectrum in Fig. 5(d) shows the spectrum from the thin part of the agglomeration over a hole in the carbon supporting film.

In contrast to some reports that the electron beam tends to change elemental oxidation state of $U$ during EEL spectra acquisitions [37] we did not observe phase transformations and the appearance of other U phases in detectable quantities.

\subsection{Determination of the particle size}

One of the main objectives of this study was to determine whether the $\mathrm{UO}_{2}$ particle sizes change with the addition of $\mathrm{Mn}$ impurities. Several techniques were applied to estimate the size of biogenic $\mathrm{UO}_{2}$ particles. The use of electron diffraction is an indirect way to determine the average size of diffracting grains while (S)TEM imaging 

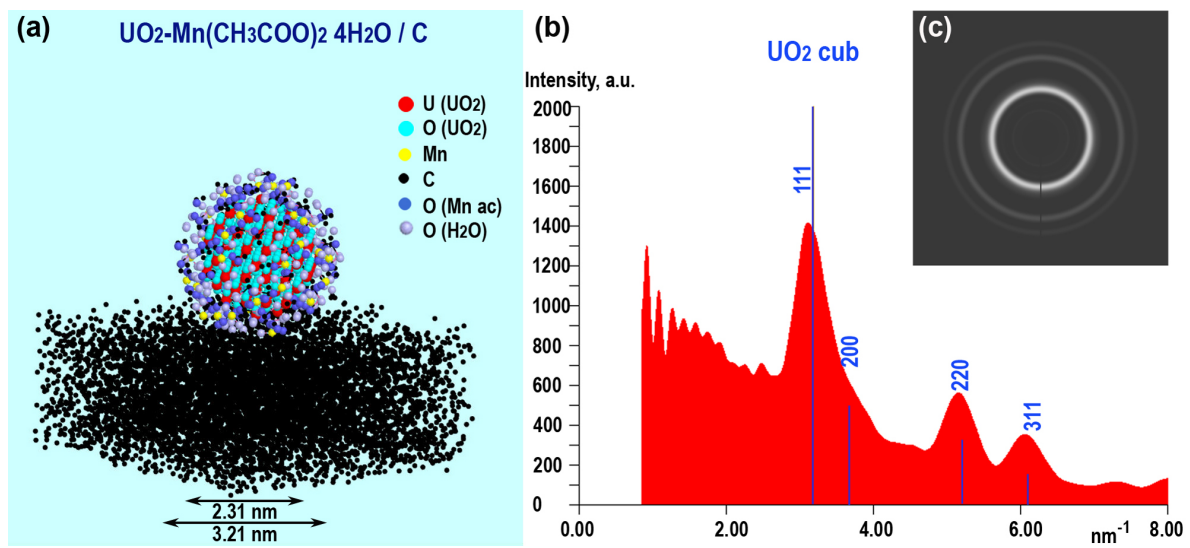

FIG. 4. Structural model of the $\mathrm{UO}_{2}$ particle of $2.31 \mathrm{~nm}$ in diameter (core) coated by $\mathrm{Mn}\left(\mathrm{CH}_{3} \mathrm{CO}_{2}\right)_{2}$ tetrahydrate (shell) of $0.9 \mathrm{~nm}$ thick on the carbon film of $2.5 \mathrm{~nm}$ thick (a), the simulated intensity profile of the diffraction rings with indicated $\mathrm{UO}_{2}$ reflections (b), the simulated ring diffraction patterns from the $\mathrm{Mn}\left(\mathrm{CH}_{3} \mathrm{CO}_{2}\right)_{2}$ tetrahydrate coated $\mathrm{UO}_{2}$ particles (c)
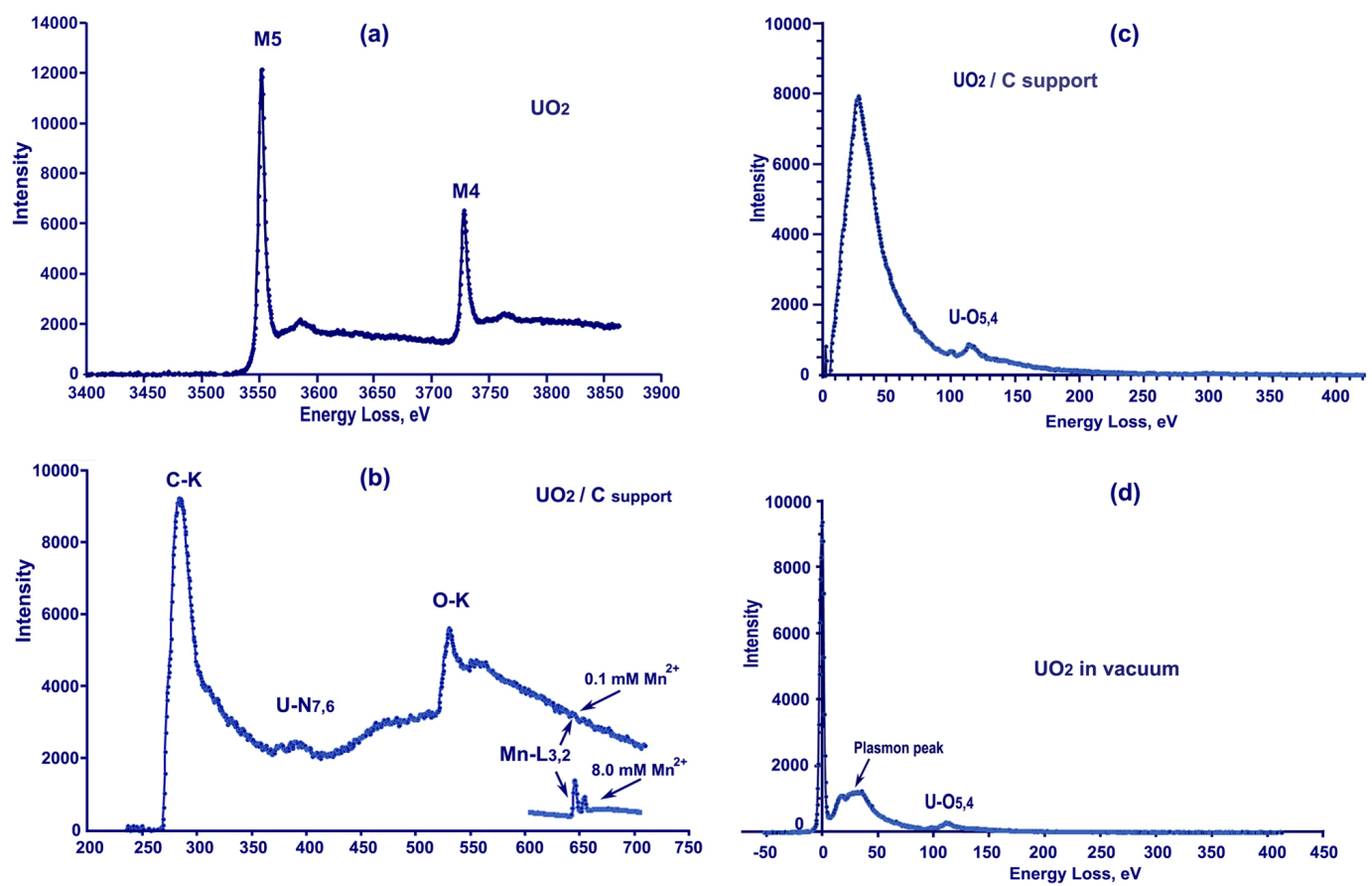

FIG. 5. U-M $\mathrm{M}_{4,5}$ EEL spectrum after background subtraction for uranium dioxide (a), U-N 7,6 , $\mathrm{O}-\mathrm{K}, \mathrm{C}-\mathrm{K}$ and $\mathrm{Mn}-\mathrm{L}_{3,2}$ (inset) EEL spectrum after background subtraction for uranium dioxide and $\mathrm{MnCl}_{2}$ on a carbon support (b), EEL spectrum obtained from the thick sample on the carbon support (c), EEL spectrum obtained from the thin sample over a hole in the carbon film in $\operatorname{vacuum}(\mathrm{d})$

offers the direct way to measure sizes and particle size distributions. However, measurements using both methods are difficult due to the small particle size and their heavy agglomeration.

The average size of particles can be found by measuring the broadened electron diffraction rings and applying the Scherrer formula. However, if the sizes of the crystal nanoparticles are less than $4 \mathrm{~nm}$, the relative error of the Scherrer formula increases significantly [38]. In this work, the simulation of powder (ring) diffraction patterns for particles with sizes in the range from $3.0 \mathrm{~nm}$ to $1.5 \mathrm{~nm}$ was performed. Afterwards the profiles of $111+200$ rings in experimental electron diffraction patterns were compared with the simulated ones. The 111 reflection was chosen because it is the strongest reflection for $\mathrm{UO}_{2}$ cubic phase and the corresponding ring is the most intense in 
SAED patterns. The other 200 ring is quite close to the 111 ring and both rings start overlapping due to size effect broadening. Therefore, the intensity profile from both reflections were analyzed.

Figure 6 shows the TEM image (Fig. (a)), the corresponding SAED pattern (Fig. 6(b)), the HRTEM image of $\mathrm{UO}_{2}$ particles (Fig. 6(c)) and the HRTEM FFT (Fig. 6(d)) obtained from the specimen containing $0.5 \mathrm{mM} \mathrm{Mn}^{2+}$. A similar observation is present in Fig. $6(\mathrm{e})$ for $\mathrm{UO}_{2}$ particles from the specimen containing $5 \mathrm{mM} \mathrm{Mn}^{2+}$. The intensities of the SAED rings (Fig. 6(f) decrease with the Mn concentrations as well the sizes of particles on the HRTEM image (Fig. 6(g)) also decrease and the rings in the FFTs become practically indistinguishable (Fig. 6(h).
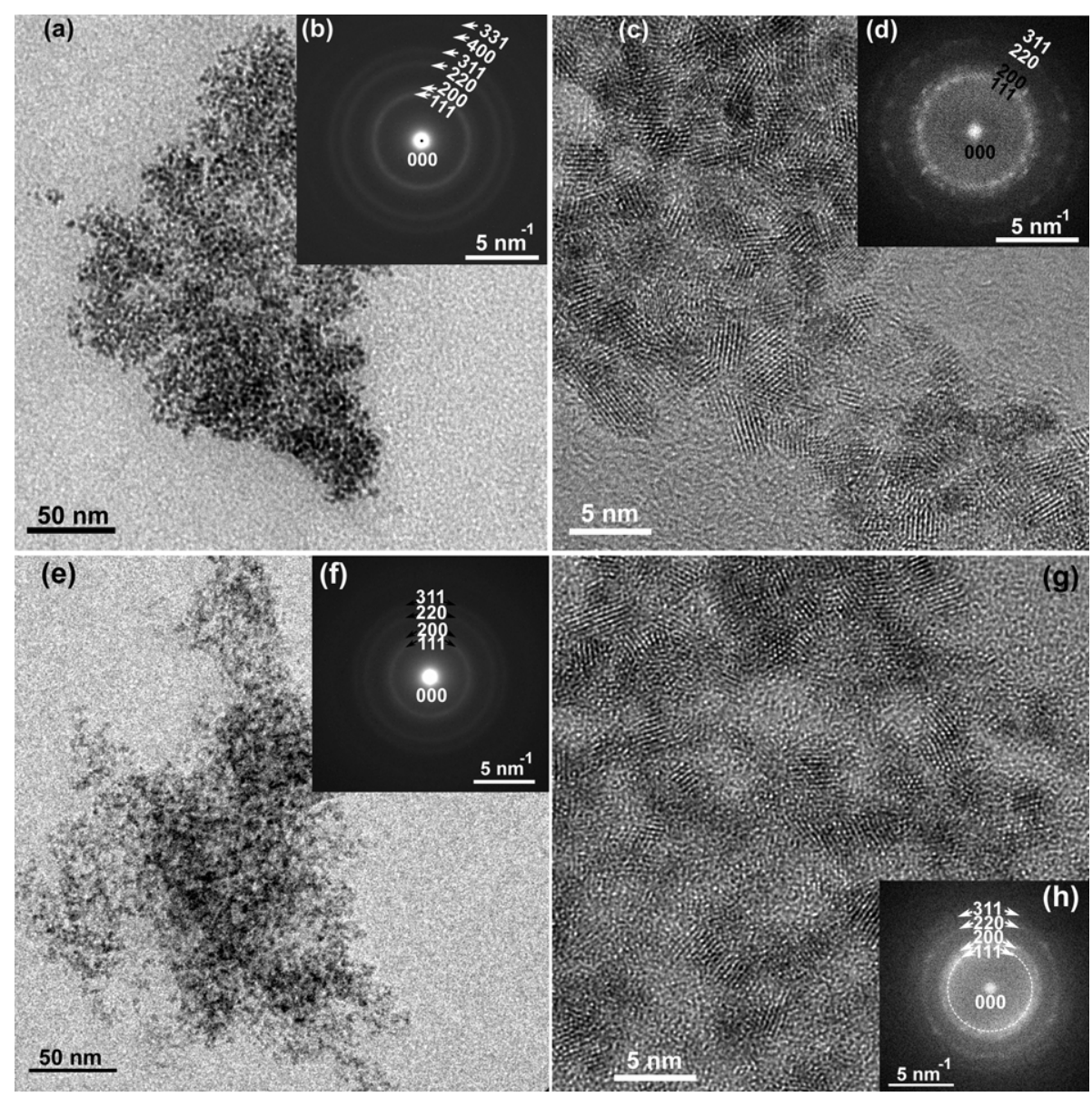

FIG. 6. TEM image of an agglomeration of $\mathrm{UO}_{2}$ particles with the low concentration of $\mathrm{Mn}^{2+}$ impurities (a), ring SAED pattern (b), HRTEM image of $\mathrm{UO}_{2}$ particles (c), FFT of the HRTEM image of $\mathrm{UO}_{2}$ particles (d); TEM image of an agglomeration of $\mathrm{UO}_{2}$ particles with the high concentration of $\mathrm{Mn}^{2+}$ impurities (e), ring SAED pattern (f), HRTEM image of $\mathrm{UO}_{2}$ particles (g), FFT of the HRTEM image of $\mathrm{UO}_{2}$ particles (h)

Analysis of the intensity profiles from both SAED patterns is shown in Figs. 7 and 8. The corresponding profiles (Figs. 7(b) and 8(b)) were recorded along the directions indicated in the SAED patterns (Figs. 7(a) and $8(\mathrm{a})$ ), the peaks, including the 111 and 200 reflections after polynomial background subtraction, are shown in Figs. 7(c) and 8(c). Finally, fitting the $111+200$ simulated peaks (dash lines in Figs. 7(d) and 8(d)) to the experimental ones was obtained for particles with the average size $2.4 \mathrm{~nm}$ and $1.9 \mathrm{~nm}$, respectively.

The average particle size (the mode diameter) was also derived from the size distributions obtained from the HRTEM images (Fig. 9(a, c)). In order to recognize the edges of small particles (specimen with higher Mn concentration) the filtered HRTEM image was analyzed (Fig. 9(d)). The smaller the size of the particles, the farther their size distribution from the Gaussian shape (Fig. 9(b, d)), approaching the right skewed lognormal distribution.

The results reported earlier [39] showed that the fastest re-oxidation is characteristic for the smallest $(\approx 1.5 \mathrm{~nm})$ biogenic $\mathrm{UO}_{2}$ particles. Adsorption of $\mathrm{Mn}$ acetates on the surface of $\mathrm{UO}_{2}$ particles and formation of the shell can explain the increase of their stability observed in [6]. 


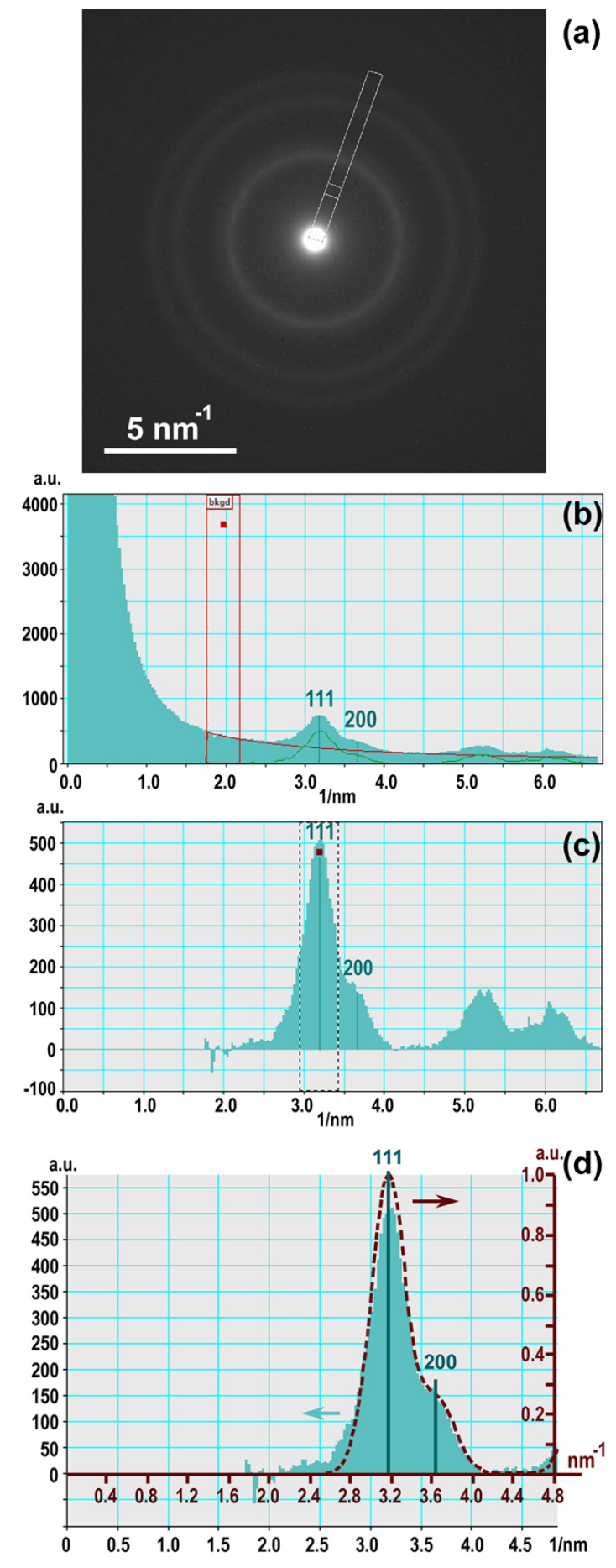

FIG. 7. Ring SAED patterns obtained from $\mathrm{UO}_{2}$ particles with low $\mathrm{Mn}^{2+}$ concentration (a), the corresponding profiles of the SAED rings (b), signal intensity of 111 and 200 reflections after background subtraction (c), fitting the calculated profile of $111+200$ reflection to the experimental intensity profile (d)
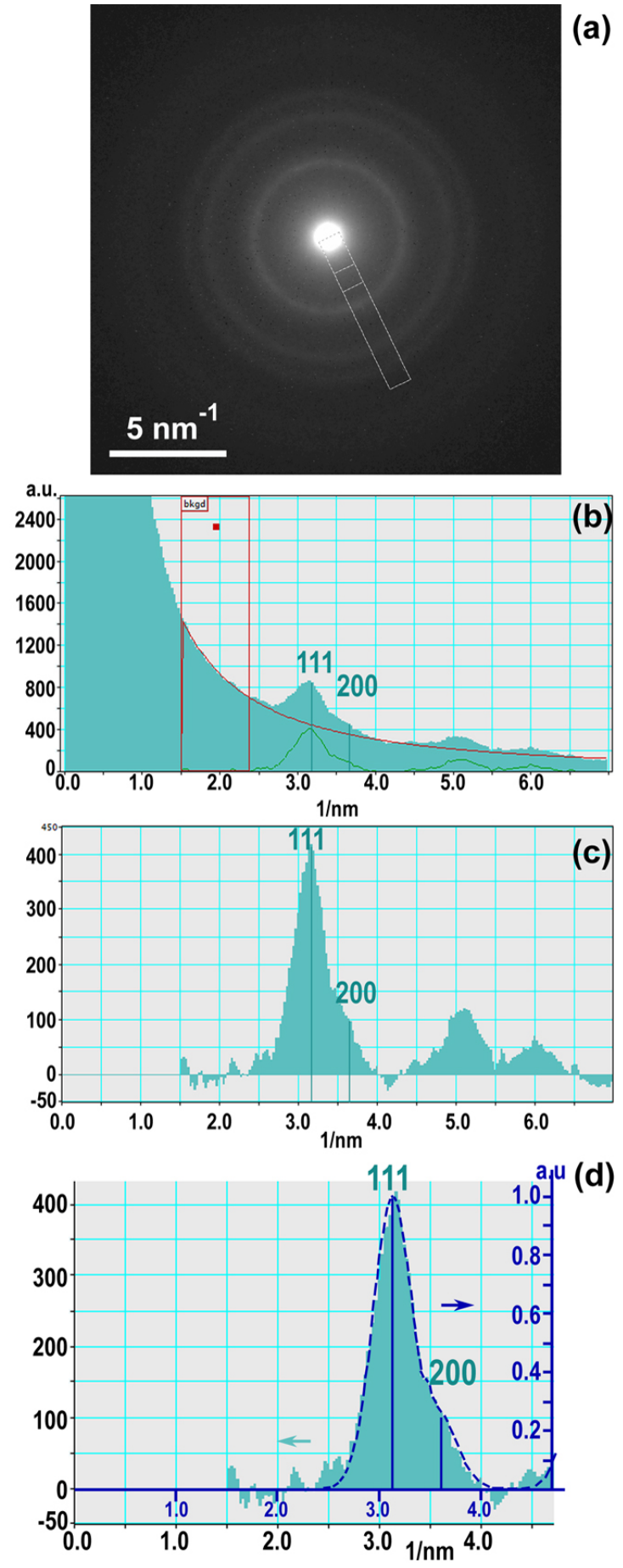

FIG. 8. Ring SAED patterns obtained from $\mathrm{UO}_{2}$ particles with high $\mathrm{Mn}^{2+}$ concentration (a), the corresponding profiles of the SAED rings (b), signal intensity of 111 and 200 reflections after background subtraction (c), fitting the calculated profile of $111+200$ reflection to the experimental intensity profile (d) 

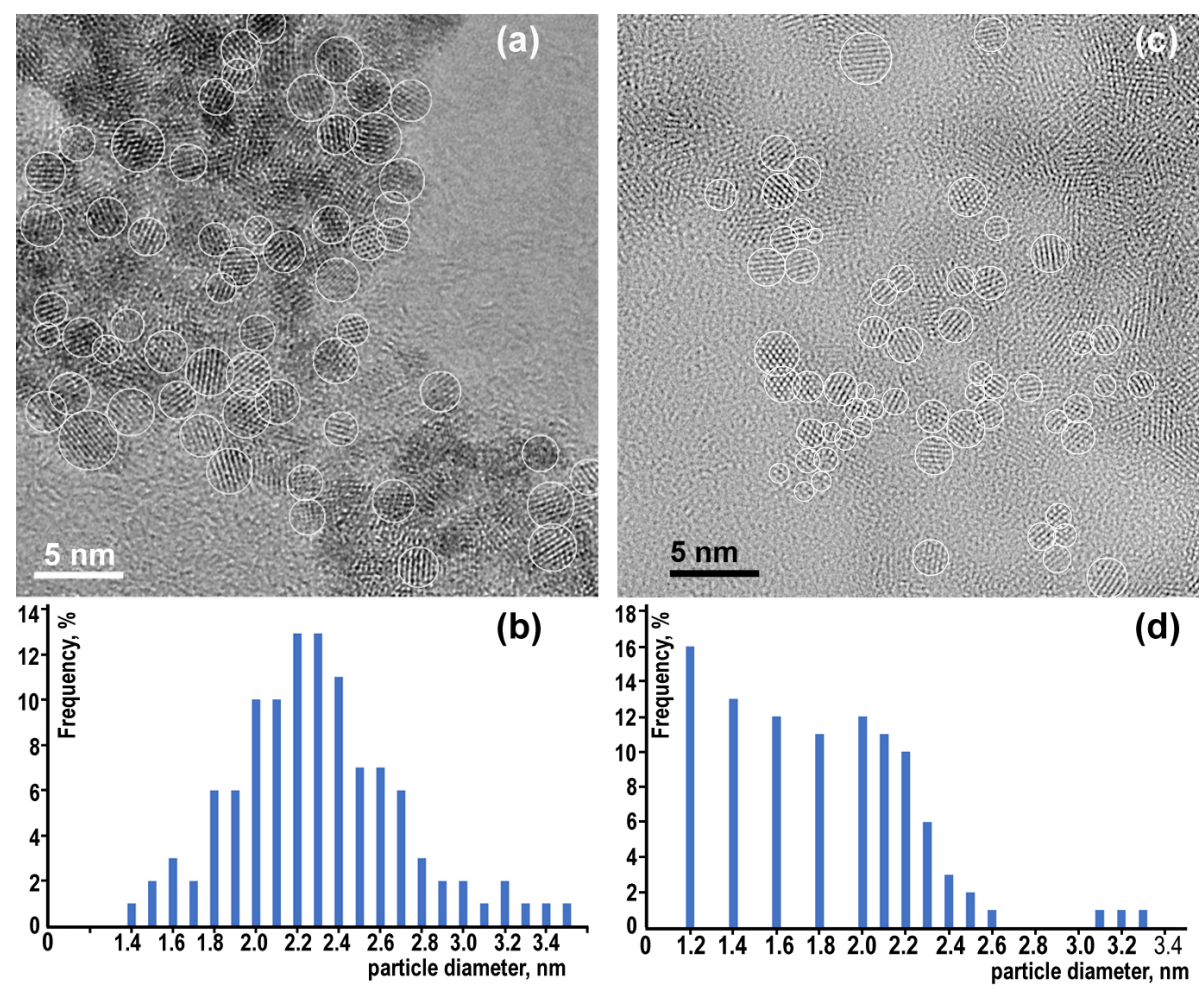

FIG. 9. HRTEM image of counted $\mathrm{UO}_{2}$ particles with measured sizes with low (a) and high $\mathrm{Mn}^{2+}$ concentration (c) and the corresponding histograms (b, d). Histograms were obtained for 100 - 120 particles from several HRTEM images

Burgos et al. [39] reported that estimation of particle sizes with EXAFS (extended X-ray absorption finestructure spectroscopy) could provide values of about $1.2 \mathrm{~nm}$ in diameter and such particles too small to be visualized by TEM what is not entirely true. Modeling the small $\mathrm{UO}_{2}$ particles and the corresponding simulation of the HRTEM images (Fig. 10) showed that it is possible to visualize particles even smaller than $1 \mathrm{~nm}$ using the microscopes without aberration corrections.

The fact is that such small particles are unlikely to survive in solution having the sizes lower than the possible critical nucleus. Simulation of small $\mathrm{UO}_{2}$ nanoparticles with non-integer number of cells showed a discrete set of sizes and the smallest particles found in HRTEM images had about $1.1-1.2 \mathrm{~nm}$ in diameter (Fig. 9(a, c)) what correspond to the model with diameter of $1.16 \mathrm{~nm}$. And the next smallest size is about $0.76 \mathrm{~nm}$. Such particles with 4 uranium atoms surrounded by 16 oxygen atoms are unikely to stay independently.

\subsection{Effect of the electron beam: Sintering of particles}

The efforts to determine the particle size distribution met the problem of the electron irradiation induced sintering. The particle sizes increased with irradiation time or/and beam intensity. Diffractograms from HRTEM images obtained during different exposure time demonstrate the increase of particle size after electron irradiation for $40 \mathrm{~s}$ (Fig. 11).

Sintering the $\mathrm{UO}_{2}$ nanoparticles did not lead to phase transformation and after 5 min of irradiation only 5.0 $9.0 \mathrm{~nm} \mathrm{UO}_{2}$ irregular particles were found. $\mathrm{Mn}$ acetate shells also did not prevent sintering and did not introduce significant effect on the final sizes and phase composition of particles. However, the amount of oxygen lowered due to radiolysis and breaking bounds in Mn acetate structure since the electron diffraction patterns showed the $\mathrm{UO}_{2}$ cubic structure.

Therefore, low dose and reasonably short exposure time should be used if the final target is to image nanoparticles and estimate their original sizes. 


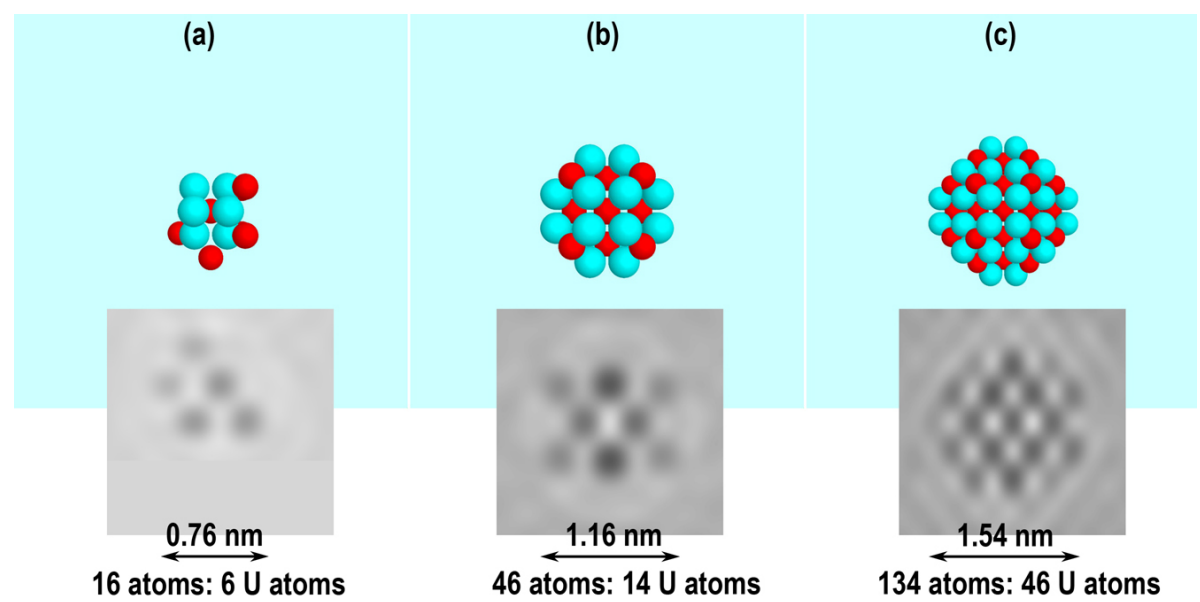

FIG. 10. The structural models of $\mathrm{UO}_{2}$ particles are built with the help of JEMS (Stadelman, JEMS 2016) with different amount of unit cells embedded in boxes with sizes $2 \times 3 \times 3$ unit cells (a), $3 \times 3 \times 3$ unit cells (b) and $4 \times 4 \times 4$ unit cells (c) with particle diameters 0.76 , 1.16 and $1.54 \mathrm{~nm}$ respectively. The HRTEM image simulation given under the corresponding model was performed using weak phase object assumption and the following imaging conditions: accelerating voltage $200 \mathrm{kV}$, spherical aberration coefficient $c s=1.4 \mathrm{~mm}$, chromatic aberration coefficient $c c=1.8 \mathrm{~mm}$, Scherzer defocus $72.5 \mathrm{~nm}$, energy spread $0.8 \mathrm{eV}$
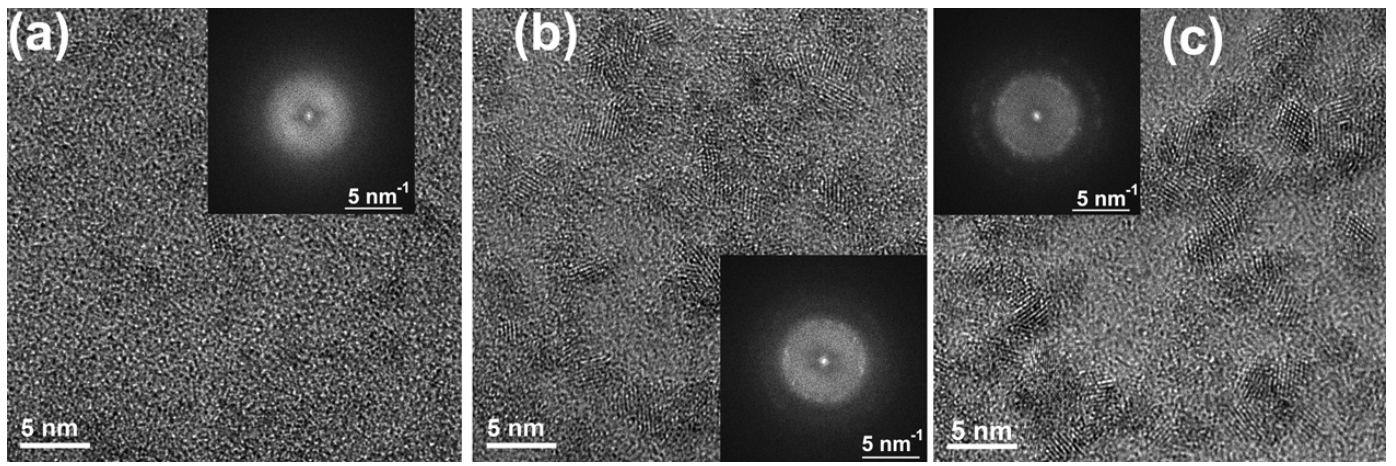

FIG. 11. HRTEM images and FFTs (insets) of $\mathrm{UO}_{2}$ nanoparticles precipitated in solutions with different concentrations of $\mathrm{Mn}^{2+}$ ions: $8.0 \mathrm{mM}$ (a), $1.0 \mathrm{mM}$ (b), $0.1 \mathrm{mM}$ (c)

\section{Conclusions}

Transmission electron microscopy analyses allowed study of the morphology and structure of biogenic nanoparticles formed during reduction of U(VI) from uranyl acetate using $S$. oneidensis MR-1 in the presence of $\mathrm{Mn}^{2+}$ impurities. $\mathrm{UO}_{2}$ nanoparticles cover the surface of cells and are agglomerated in extracellular space. Their sizes decrease with increase of concentration of impurity $\mathrm{Mn}^{2+}$ ions in the solutions. Quantitative X-ray EDS microanalysis showed that $\mathrm{Mn}$ acetate tetra- or dihydrate formed and strongly adsorbed on the particle surface, which may explain suppression of $\mathrm{UO}_{2}$ particle growth and the increase in particle stability and dissolution resistance. The $\mathrm{UO}_{2}$ particles have a strong tendency to sinter under the electron beam and their size increases markedly while the presence of $\mathrm{Mn}$ acetate shell has no effect on the sintering process. Some elongated particles of approximately $8.0-9.0 \mathrm{~nm}$ long with irregular shape formed during sintering. The $\mathrm{UO}_{2}$ phase is quite stable under electron beam and does not undergo phase transitions. The process of biogenic removal of $\mathrm{U}^{6+}$ from contaminated water can be efficient also for the simultaneous removal of $\mathrm{Mn}^{2+}$ ions.

\section{Acknowledgements}

All samples were prepared at École Polytechnique Fédérale de Lausanne (EPFL). The help of Prof. Philippe Buffat in discussions of results is acknowledged. This work was also supported by the Ministry of Science and Higher Education of the Russian Federation. 


\section{References}

[1] Gadd G.M. Microbial influence on metal mobility and application for bioremediation. Geoderma, 2004, 122, P. 109-119.

[2] Newsome L., Morris K., et al. The stability of microbially reduced U(IV); impact of residual electron donor and sediment ageing. Chemical Geology, 2015, 409, P. 125-135.

[3] Post J.E. Manganese oxide minerals: Crystal structures and economic and environmental significance. Proc. Natl. Acad. Sci. USA, 1999, 96, P. 3447-3454.

[4] Taffarel S.R., Rubio J. Removal of $\mathrm{Mn}^{2+}$ from aqueous solution by manganese oxide coated zeolite. Minerals Engineering, 2010, 23, P. $1131-1138$.

[5] Williams D.B., Carter C.B. Transmission Electron Microscopy. A Textbook for Materials Science (Second Ed.), Springer, 2009.

[6] Middleton S.S., Bencheikh Latmani R., et al. Cometabolism of Cr(VI) by Shewanella oneidensis MR-1 Produces Cell-Associated Reduced Chromium and Inhibits Growth. Biotechnology and Bioengineering, 2003, 83, P. 627-637.

[7] Schofield E.J., Veeramani H., et al. Structure of Biogenic Uraninite Produced by Shewanella oneidensis Strain MR-1. Environ. Sci. Technol., 2008, 42, P. 7898-7904.

[8] Veeramani H., Schofield E.J., et al. Effect of Mn(II) on the Structure and Reactivity of Biogenic Uraninite. Environ. Sci. Technol., 2009, 43, P. 6541-6547.

[9] Veeramani H., Alessi D.S., et al. Products of abiotic U(VI) reduction by biogenic magnetite and vivianite. Geochimica et Cosmochimica Acta, 2011, 75, P. 2512-2528.

[10] Stadelmann P. JEMS (Java Electron Microscopy Software); software available at URL: http://www.jems-saas.ch/.

[11] Wasserstein B. Ages of uraninites by a new method. Nature, 1954, 174, P. 1004-1005.

[12] Rundle R.E., Baenziger N.C., et al. The Structures of Carbides, Nitrides and Oxides of Uranium. J. American Chemical Society, 1948, 70, P. 99-105.

[13] Loopstra B.O., Taylor J.C., Waugh A.B. Neutron powder profile studies of the gamma uranium trioxide phases. Journal of Solid State Chemistry, 1977, 20, P. 9-19.

[14] Siegel S. The crystal structure of trigonal $\mathrm{U}_{3} \mathrm{O}_{8}$. Acta Cryst., 1955, 8, P. 617-619.

[15] Andresen A.F. The structure of $\mathrm{U}_{3} \mathrm{O}_{8}$ determined by neutron diffraction. Acta Cryst., 1958, 11, P. $612-614$.

[16] Cooper R.I., Willis B.T.M. Refinement of the structure of beta-( $\left.\mathrm{U}_{4} \mathrm{O}_{9}\right)$. Acta Cryst. A, 2004, 60, P. $322-325$.

[17] Levi G.R. The crystal structure of MnO. Mathematiche e Naturali, 1924, 57, P. 619-624.

[18] Radler M.J., Cohen J.B., et al. The defect structures of $\mathrm{Mn}_{1-x}$ O. Journal of Physics and Chemistry of Solids, 1992,53 , P. $141-154$.

[19] Min N.K., Yong-Il K., et al. New crystal structure: synthesis and characterization of hexagonal wurtzite MnO. Journal of the American Chemical Society, 2012, 134, P. 8392-8395.

[20] Klein H., David J. The quality of precession electron diffraction data is higher than necessary for structure solution of unknown crystalline phases. Acta Cryst. A, 2011, 67, P. 297-302.

[21] Baron V., Gutzmer J., Tellgren, R. The influence of iron substitution on the magnetic properties of hausmannite, $\mathrm{Mn}(2+)(\mathrm{Mn}, \mathrm{Fe})_{2}(3+) \mathrm{O}_{4}$. American Mineralogist, 1998, 83, P. 786-793.

[22] Norrestam R., Alpha-manganese (III) oxide - a C-type sesquioxide of orthorhombic symmetry. Golden Book of Phase Transitions, Wroclaw 2002, 1, P. 1-123.

[23] Rogers D.B., Shannon R.D., Sleight A.W., Gillson J.L. Crystal chemistry of metal dioxides with rutile-related structures. Inorganic Chemistry, 1969, 8, P. 841-849.

[24] Nuss J., Pfeiffer S., van Smaalen S., Jansen M. Structures of incommensurate and commensurate composite crystals $\mathrm{Rb}(x) \mathrm{MnO} \mathrm{O}_{2}(x=$ 1.3711, 1.3636). Acta Cryst. B, 2010, 66, P. 27-33.

[25] Post J.E., Heaney P.J. Neutron and synchrotron X-ray diffraction study of the structures and dehydration behaviors of ramsdellite and "groutellite". American Mineralogist, 2004, 89, P. 969-975.

[26] Fredrickson J.K., Zachara J.M., et al. Influence of Mn oxides on the reduction of uranium(VI) by the metal-reducing bacterium Shewanella putrefaciens. Geochimica et Cosmochimica Acta, 2002, 66, P. 3247-3262.

[27] Saratovsky I., Wightman P.G., et al. Manganese Oxides: Parallels between Abiotic and Biotic Structures. J. Am. Chem. Soc., 2006, 128, P. 11188-11198.

[28] Bertaut E.F., Duc T.Q., et al. Crystal Structure of Manganese Acetate Tetrahydrate. Acta Cryst. B, 1974, 30, P. 2234-2236.

[29] Cheng C.-Y., Wang S.L. Structure of manganese acetate dihydrate. Acta Cryst. C, 1991, 47 (8), P. 1734-1736.

[30] Francis A.J., Dodge C.J., et al. XPS and XANES Studies of Uranium Reduction by Closfridium sp. Environ. Sci. Technol., 1994, 28, P. 636-639.

[31] Martin J.D., Hess R.F. $\beta$ - $\mathrm{Mn}\left(\mathrm{O}_{2} \mathrm{CMe}\right)_{2}$ : solvothermal synthesis and crystal structure of an unprecedented three-dimensional manganese (II) network. J. Chem. Soc. Commun., 1996, 21, P. 2419-2420.

[32] Lanovetskiy S.V., Poylov V.Z., Stepanov A.V. Physicochemical Fundamentals of Obtaining High Purity Manganese (II) Acetate Tetrahydrate. Chemistry for Sustainable Development, 2012, 20, P. 173-179.

[33] Linke W.F. Solubilities, Inorganic and Metal Organic Compounds: A Compilation of Solubility Data from the Periodical Literature, Band 2, Van Nostrand, 1965.

[34] Wyckoff R.W.G. Pyrochroite. Crystal Structures 1, 2nd edition. Interscience Publishers, New York, 1963, P. $239-444$.

[35] Taffarel S.R., Rubio J. Removal of $\mathrm{Mn}^{2+}$ from aqueous solution by manganese oxide coated zeolite. Minerals Engineering, 2010, 23, P. 1131-1138.

[36] Buck E.C., Fortner J.A. Detecting low levels of transuranics with electron energy loss spectroscopy. Ultramicroscopy, 1997, 67, P. 69-75.

[37] Rice S.B., Bales H.H., Roth J.R., Whiteside A.L. Empirical Identification of Uranium Oxides and Fluorides Using Electron Energy-loss Spectroscopy in the Transmission Electron. Microscope. Microsc. Microanal., 1999, 5, P. 437-444.

[38] Vorokh A.S. Scherrer formula: estimation of error in determining small nanoparticle size. Nanosyst. Phys., Chem., Math., 2018, 9 (3), P. 364-369.

[39] Burgos W.D., McDonough J.T., et al. Characterization of uraninite nanoparticles produced by Shewanella oneidensis MR-1. Geochimica et Cosmochimica Acta, 2008, 72, P. 4901-4915. 